\title{
Luck-Neutralization: A Defense
}

\author{
Teun J. Dekker
}

Published online: 25 February 2010

(C) The Author(s) 2010. This article is published with open access at Springerlink.com

The value of luck-neutralization, the idea that a society should strive to neutralize the differential effects of luck on how well the lives of its members go, seems a highly attractive and morally important social goal. Hence it is hardly surprising that luck-neutralization has featured prominently in social and political thought. Perhaps the most important contemporary elaborations of this ideal can be found in the field of distributive justice. For many years celebrated theorists of social justice, such as G.A. Cohen, John Roemer, Richard Arneson, and, to some extent, Ronald Dworkin have argued that achieving justice requires that society neutralize the impact of luck on the distribution of burdens and benefits. ${ }^{1}$ They seek to achieve this by equalizing the effects of luck over all members of society. In this way, these theorists deduce from luck-neutralization theories of justice that are egalitarian in nature.

Susan Hurley has argued that the ideal of luck-neutralization provides no reason to establish an egalitarian pattern of distribution. ${ }^{2}$ Any such pattern must be justified through some other ideal, such as equality. In response to this attack, several prominent luck-egalitarians have, to some extent, abandoned luck-neutralization and settled for damage control. G.A. Cohen has argued that fairness, and not luckneutralization stands at the basis of his luck-egalitarianism. ${ }^{3}$ Although he accepts

\footnotetext{
1 See G. A. Cohen, "On the Currency of Egalitarian Justice," Ethics, vol. 99, no. 4 (1989); see also John E. Roemer, Equality of Opportunity (Cambridge, Mass.: Harvard University Press, 1998); Richard Arneson, "Equality and Equal Opportunity for Welfare." Philosophical Studies, vol. 56, no. 1 (1989); and Ronald Dworkin, Sovereign Virtue: The Theory and Practice of Equality (Cambridge, Mass.: Harvard University Press, 2000).

2 See Susan Hurley, Justice, Luck, and Knowledge (Cambridge, Mass.: Harvard University Press, 2003).

3 See G. A. Cohen, "Luck and Equality: A Reply to Hurley," Philosophy and Phenomenological Research, vol. 72, no. 2 (2006). pp. 439-446.
}

T. J. Dekker $(\bowtie)$

University College Maastricht, Zwingelput 4 - 6211 KH, P.O. Box 616 - 6200 MD, Maastricht,

The Netherlands

e-mail: teun.dekker@maastrichtuniversity.nl 
that luck-neutralization does some work, he argues that its appeal is fundamentally derivative. John Roemer has admitted that the purpose of his theory is to reward desert in an equitable fashion. ${ }^{4}$ Richard Arneson has sought to find other arguments for luck-egalitarianism, lessening its dependence on luck-neutralization, calling the ideal incoherent and confused. ${ }^{5}$

This response is mistaken. The ideal of luck-neutralization has great intuitive appeal and should not be abandoned as lightly as it has. The fact that Hurley has identified several problems with traditional thinking about luck-neutralization is a reason to re-examine the concept, not to discard it. Here, the ideal of luckneutralization will be defended by arguing that luck-neutralization can form the basis of an egalitarian theory of justice similar to those advanced under the banner of luck-egalitarianism. Hurley's challenge will be met by presenting an account of luck-neutralization, called universal access to every available advantage, which is egalitarian without relying on equality or any other concept foreign to luckneutralization. The focus of this defense of luck-neutralization, like Hurley's critique, lies exclusively on the determinacy of that ideal. The sole aim is to show that the ideal leads to an egalitarian conception of justice, and not with showing that the ideal of luck-neutralization is attractive.

\section{The Ideal of Luck-Neutralization}

The ideal of luck-neutralization seems simple enough. It is the idea that the influence of luck on our lives, and in particular the levels of advantage individuals enjoy, should be eradicated. Luck is a pervasive force in human existence. There are few aspects of our lives that are not touched by it, if only to some extent. This appears morally problematic. It seems in some way wrong that luck has this enormous influence on how an individual's life goes. ${ }^{6}$ In the context of distributive justice, the ideal governs how the burdens and benefits inherent in social cooperation are distributed and how various levels of advantage are assigned to particular individuals. When we look at actual societies, we cannot help but notice how luck plays a large part in the assignment of the levels of advantage, through the educational opportunities that are afforded to some individuals but not others or through the talents some individuals have and others lack. From the perspective of luck-neutralization, the influence of luck is unjust and its influence on how society allocates levels of advantage should be eradicated.

Following G.A. Cohen, advantage is a vector of goods that it advantageous to have, including but not limited to resources and welfare. ${ }^{7}$ As such, it is a multidimensional metric that allows us to give an all-encompassing insight into how well off an individual is. A level of advantage simply denotes a social position that is

\footnotetext{
${ }^{4}$ See John E. Roemer, "Defending Equality of Opportunity," The Monist, vol. 86 no. 2 (2003), p. 279.

5 See Richard Arneson, "Luck and Equality," Proceedings of the Aristotelian Society, vol. 75 (2001).

6 See Bernard Williams, "Moral Luck," in Bernard Williams, Moral Luck: Philosophical Papers1973-1980 (Cambridge, England: Cambridge University Press, 1981).

7 See Cohen, “On the Currency of Egalitarian Justice," p. 916.
} 
associated with some level of advantage. It is exclusively defined by how much advantage is associated with the position. Although it is possible that several distinct social roles or jobs are equivalent in the advantage they offer, for present purposes these social positions all count as the same level of advantage.

The distinction between levels of advantage and social positions is important, because it resolves an often-mentioned criticism to theories of justice that equalize access to advantage. It is often objected that not all individuals can be doctors, generals, or captains of industry. These social positions are by their very nature restricted, but bring great benefit to society. Equalizing access to advantage might seem to require that even unqualified individuals be allowed into these types of professions or that such positions are eliminated. Both policies would have disastrous social consequences. However, egalitarian theories of justice are about levels of advantage, rather than about social positions or concrete jobs. It is not unjust that some people can be pilots while others cannot, but it is unjust that people who have the ability to be pilots can achieve levels of wellbeing that others cannot. As long as people who cannot become pilots can, through some other path open to them, end up as well off as people who can become pilots, justice is attained without undesirable social consequences.

Here, the term "luck" may be defined as some force or fact over which an individual has no control and which has an impact on how well off the individual is. As such, luck stands opposed to control, albeit a particular type of control. In the literature on luck-egalitarianism luck is opposed to responsibility. Only factors for which individuals are responsible may result in some being worse off than others, while factors for which individuals are not responsible may not lead to inequalities. However, given the problematic philosophical nature of responsibility, a convention has arisen in the literature to contrast luck with control, or some similar notion. In this context, Dworkin uses the concept of ambition sensitivity. ${ }^{8}$ Likewise, Cohen opposes "chance" to "choice." 9 However, the use of the more expedient and euphonious terms should not distract from the fact that the fundamental concept is one of responsibility. Hence, this type of control does take into account differences among individuals for which they are not responsible, including differential talents and social circumstances, so as to ensure that no factors that are morally arbitrary influence how well off one is. This is also why the phrase "access to advantage" is used, rather than the related phrase of "opportunity for advantage." As Cohen notes, meager personal capacity might not detract from one's opportunities, but it does limit one's access to advantage. ${ }^{10}$ Hence, "control" should be understood as responsible control, and the current use of the term follows this convention in the literature. To say that someone has access to a particular level of advantage is to say that the person can, given his or her choice making and choice implementing skills, achieve that level of advantage. Included in this conception of control is the concept of option luck, how gambles that individuals have deliberately taken happen to turn

\footnotetext{
${ }^{8}$ See Dworkin, op. cit., p. 89.

9 See Cohen, "On the Currency of Egalitarian Justice," p. 934.

${ }^{10}$ See ibid., 916-917.
} 
out. ${ }^{11}$ As individuals may be deemed responsible for taking the risks, and could have avoided being exposed to them, the ideal of luck-neutralization is not compromised when such gambles have an impact on how well off individuals are.

Several prominent theories of justice have been designed to elucidate what neutralizing luck would require. An important feature of the theories is that they are egalitarian in nature. They would have us neutralize the differential effects of luck by equalizing them. For example, let us consider G.A. Cohen's presentation of luckegalitarianism. Cohen's version is summed up by the ideal of equality of access to advantage. Someone is not deemed responsible for the access the person has to advantage, since this is ultimately a function of the circumstances that the person is in. In this context, Hurley speaks of goods that are a matter of luck, but this notion is the same as Cohen's notion of access to advantage. After all, Hurley wishes to criticize Cohen's theory on its own terms. For Cohen, access to advantage is the thing which is to be distributed equally, and in Hurley's reconstruction of Cohen's theory, the thing to be distributed equally is goods for which individuals are not responsible. This is a purely terminological issue, and the two notions are the same. Access to advantage includes all factors that we have no control over, but which have an influence on how well off individuals are. However, what we do with the access to advantage that we enjoy is a matter of individual control, and hence any outcomes that result from the exercise of the capacity for control are deemed just. The theory is egalitarian because it allows us to stipulate that access to advantage by individuals must be equal. In this way, luck-egalitarians see in luck-neutralization the basis of an egalitarian theory of justice.

This last contention is what Hurley wishes to challenge. Central to Hurley's argument is the distinction she coins between patterns and currencies of distribution. ${ }^{12}$ This important distinction separates the questions what should be distributed and how it should be distributed. The currency of distribution is the thing that a theory of distributive justice would have society distribute. The pattern is the way in which that currency should be distributed. To give an example, someone might agree that the currency of distributive justice is money, and yet disagree whether that money should be distributed in an equal fashion or not. This distinction is important, because Hurley claims that while luck-neutralization can specify the currency of justice, in this context access to advantage, it cannot justify any specific pattern of distribution, including the egalitarian pattern of distribution luck-egalitarianism stipulates. She notes that "the aim to neutralize luck cannot provide a basis for egalitarianism. It can neither (nontrivially) specify nor justify an egalitarian pattern of distribution." 13

In particular, Hurley posits that luck-neutralization cannot provide a reason to institute a more equal distribution of some currency of justice. This is the justification argument, which we will take up. ${ }^{14}$ The central claim of a proponent of this argument is that one cannot derive an egalitarian theory of justice, such as equality of access to

\footnotetext{
11 See Dworkin, op. cit., pp. 73-83.

12 See Hurley, op. cit., pp. 146-155.

13 Ibid., p. 179.

14 See ibid., p. 147.
} 
advantage, from the ideal of luck-neutralization without making explicit egalitarian assumptions that are foreign to the ideal of luck-neutralization. The challenge is to find an argument with only luck-neutralization in the premises, but with equality in the conclusion. Such an argument would undermine Hurley's position. To act as a benchmark, Hurley institutes the egalitarian constraint. For Hurley, a theory is egalitarian if, for some currency of justice, it favors "relatively more equal patterns of distribution of [that currency] over relatively less equal patterns of [that currency], other things being equal." 15

The main argument for Hurley's claim that luck-neutralization provides no basis for egalitarianism is the luck-neutralizer's dilemma. Through this dilemma Hurley argues that luck-neutralization cannot justify an egalitarian pattern of distribution. The luck neutralizer's dilemma relies on the idea that we may mean two things when we say that someone has good or bad luck. ${ }^{16}$ One reading of having a particular type of luck is interpersonal, and it depends on whether or not someone's luck is worse or better than someone else's luck. As Hurley puts it: "I have bad luck when what I and others have is a matter of luck, and I have less than others." 17 Alternatively we may conceive of bad or good luck as counterfactual. In this case, luck-egalitarians "compare our actual situation with other possible situations [we] might have been in. I have bad luck when what I have is a matter of luck and I am worse off than I might have been."18

If we think of having good or bad luck in the interpersonal sense, then whether or not someone has bad luck depends on how the person's luck relates to the luck others face. The badness of luck is defined in a comparative sense. Under this specification neutralizing luck does require its equalization. But this specification of bad luck itself relies on a commitment to equality. In this way, luck-neutralization is not a reason for egalitarianism.

Neutralizing counterfactual luck does not imply equalizing it across individuals, or so Hurley suggests. If someone is worse off than he or she might have been in some other world, then in order to neutralize luck, we must either eliminate the other world or put the individual in the best world possible for the individual. However, Hurley argues that there is no reason to suppose that doing this across the population will result in an equal distribution of goods the distribution of which is a matter of luck. Again, there is no particular pattern generated by neutralizing luck in this sense, let alone an equal pattern.

\section{Lives of Luck and Control}

Hurley's claim will be refuted by an elaboration of luck-neutralization that does not rely on any appeals to equality or desert to justify an egalitarian pattern of distribution. It is helpful to start the investigation into what a society in which luck

\footnotetext{
15 Ibid., p. 147.

16 See ibid., 155-159.

17 See ibid., p. 156.

18 Ibid., p. 156.
} 
plays no role would look like by considering its opposite, a society in which someone's distributive position is entirely a matter of luck. In such a society, no one has any control over the distributive positions he or she occupies. The members of the society are entirely dependent on chance for their level of advantage. For example, we may imagine a society in which social positions are distributed by lottery. The level of advantage an individual occupies in such a society is entirely fixed by his or her draw in the lottery. A very rigid caste society approaches such a life of luck in certain respects. In a caste society, a person's distributive level is entirely a function of the caste that the person is born into. However, in all such cases, the life prospects of individuals are entirely determined by factors for which they are not responsible. In this way, luck determines a person's level of advantage. Anyone who supports the ideal of luck-neutralization would abhor such a society. The point of the ideal is to ensure that luck plays no part in how well off a person is. A society in which everyone lives a life of luck is just what luck-neutralizers do not want.

Reflecting on a life of luck forces us to consider the question what the opposite of such a life would be. What is it to not depend on luck for our level of advantage at all? As luck is everything over which individuals do not have any control and which has an impact on how well their lives go, to depend on luck is to depend on factors beyond our own control. The inverse correlate of this is to depend for our level of advantage on factors that are within our control. In such a life, how well off someone is depends exclusively on factors that are within his or her control, and luck plays no role. The only thing that matters for how well off the person is, is how the person has exercised his or her capacity for control.

In this way, a life of total control would be a life in which we have access to every available level of advantage in society. In such a life, luck has no influence on how well off someone becomes, and for that reason it lives up to the ideal of luckneutralization. Presumably, whatever outcome ensues would be deemed just, as it is hard to imagine how someone could object to a distribution that is solely a product of his or her own choice. ${ }^{19}$ People who have access to every level of advantage cannot hold luck responsible for their distributive share; they could have, through exercising their capacity for control appropriately, achieved any distributive level. In that sense, the influence of luck is neutralized. At the same time, if someone has access to some, but not all, levels of advantage, a fact assumed to be beyond his or her control, luck does influence the level that the person comes to occupy. In this case, luck limits the person's choices, by making it impossible to achieve certain levels and plays a role in determining where the person ends up. A caste society is an extreme case of this, as it gives individuals access to only one level of advantage. Hence, a life of control, one that is characterized by access to every level of advantage, is a life in which the ideal of luck-neutralization is satisfied. Such a life of control is fundamentally non-comparative in nature. Whether someone lives such a life depends entirely on whether the person has available options that could lead to every level of advantage available in society.

\footnotetext{
${ }_{19}$ See Thomas Scanlon, What We Owe to Each Other (Cambridge, Mass.: Harvard University Press, 1998), p. 258.
} 
To put the idea of a life of control in the framework advanced by Arneson, we might imagine a social menu. ${ }^{20}$ Such a menu contains all the levels of advantage that a society can offer its members. It is possible to compare decision trees of individuals and the levels of advantage at the ends of their branches with the social menu. If the two map onto one another and both contain the same levels of advantage, an individual lives a life of control, as required by the ideal of luckneutralization. If, however, someone's decision tree offers access to fewer levels of advantage than figure on the social menu, the person does not have access to every available level of advantage. This means that luck influences, at least to some degree, the level a person achieves. By definition, it is impossible to have access to more advantages than there are on the social menu.

To achieve luck-neutralization, we must determine what levels are available on the social menu, and expand an individual's access to advantage to give the individual access to every level of advantage on the menu. It is clear that the levels of advantage on the menu depend on what a society can offer its members, given the resources it has at its disposal. As such, it is primarily a function of the amount of advantage to be distributed. A well-resourced society can offer its members access to higher levels of advantage than societies that have fewer resources. However we might delineate societies, for current purposes it will simply be assumed that a society is a closed and clearly defined entity. While it may be bad luck in some sense to live in a society that cannot offer individuals access to levels of advantage which are beyond its means, this is not the bad luck luck-neutralization should be concerned with. The problem of distributive justice concerns how the burdens and benefits that result from social cooperation should be distributed and not how advantages that are not there should be distributed.

However, there is another constraint on which levels of advantage appear on the social menu. A level of advantage can only be on the social menu if it can be made generally available, if all members of society can, given limited resources, be offered the level. This restriction on the social menu is required to achieve luckneutralization. If a level of advantage is available to some individuals in society, individuals who lack access to it may point to the fact that some individuals do have access to it as evidence for the claim that they lack access to every level in society. According to the ideal of luck-neutralization, this should be remedied in some way. Ideally, everyone should have access to that level of advantage, but since that is impossible, the only option is to make that level generally unavailable. If this level were allowed to be available to some but not all members of society, how well off individuals end up would not be entirely within their control. This would also depend on whether or not the individuals had access to the disputed levels of advantage, which is by definition a matter of luck. Only if a level of advantage is available to everyone in society can it be available in a society in which luck is neutralized. Hence, the social menu contains all levels of advantage that a society can, given its resources, make available to all its members.

This restriction on what counts as an available level of advantage is not based on an external commitment to equality; that would concede Hurley's challenge. It is

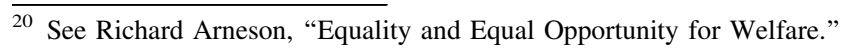


not the case that equalizing access to advantage neutralizes luck by itself, but merely that a level of advantage cannot count as available in society that neutralizes luck unless it is available to all. If a level of advantage can be made available to some individuals but not others, luck is not neutralized, though not because of the inequality as such but because it shows that all individuals do not have access to every level of advantage. The inequality is evidence of the fact that luck is not neutralized for everyone, but not the source of this fact, which is thee distinct fact that not all members of society have access to every level of advantage.

This is an important issue, which requires further elaboration to ensure that this specification of the life of control does not implicitly rely on an egalitarian commitment. After all, it might appear that the two-step procedure of defining a social menu and ensuring that all have access to all levels on this menu that is under consideration merely hides the egalitarian element. By claiming that levels of advantage can only be included in the social menu if they can be made universally available, we are in effect defining "bad luck" as not having access to levels of advantage that others do have access to. Hence "bad luck" is defined in the interpersonal sense, and the scheme falls prey to the first horn of the luckneutralizer's dilemma.

However, this is not the case. While having worse access to advantage than others is incompatible with the life of control that luck-neutralization requires, it is not the case that having the same access to advantage as others ensures that someone lives a life of control. Inequalities are, in that sense, a symptom of a deeper problem of not having access to every available level of advantage. This sometimes manifests itself through an inequality, but such inequalities are not intrinsically problematic. On other occasions, the fundamental problem can occur without there being an inequality. We might imagine a perfectly egalitarian distribution of access to advantage, but where society could, but does not, make available some higher level of advantage to all. Individuals in such a society do not have access to all levels of advantage, and hence do not live a life of control in the relevant sense. Hence this is a suboptimal situation. However, as the pattern of distribution is already perfectly equal, this cannot be due to a prior commitment to equality.

To establish whether an individual enjoys a life of control, we must ask whether someone has access to every available level of advantage. If some individuals have better access to advantage than others, we can say that there are some individuals who do not have access to every available advantage. In one sense, this is due to the inequality, inasmuch as the inequality shows that there is a problem. But in a more fundamental sense, the problem is not caused by the relative inequality, but by the absolute deviation from the life of control. To see this, let us consider a well known analogy drawn by Derek Parfit. ${ }^{21}$ People on a mountain find it more difficult to breathe than people in the surrounding valley. Is that because they are higher up than others? Parfit argues that, in the relevant sense, while the different experiences are correlated with the inequality, their true cause lies in the lack of oxygen on the mountain.

\footnotetext{
${ }^{21}$ See Derek Parfit, "Equality and Priority," Ratio, Vol. 10, No. 3 (1997), p. 214.
} 
Hence people who complain that they do not enjoy a life of control because others have superior access to advantage, are not objecting to the equality per se, but use it as evidence of the fact that they do not have access to every level of advantage. That is why society must ensure that there are no levels of advantage that some people have access to but others do not. Only by deleting the levels entirely, rather than simply removing individuals from them, can society ensure that individuals can, through responsible choices, achieve every level of advantage available in society. Inequalities in access to advantage are bad, not because they are inequalities, but because they are evidence of some individuals not having access to every available level of advantage in society.

But they are merely evidence. Leveling down the more fortunate individuals, while not redistributing access to advantage or making the levels generally unavailable, does not remove the fundamental problem, even if it removes the inequality. This is simply the egalitarian but suboptimal distribution of access to advantage that was considered above. This shows that luck, as it is related to the life of control is not specified interpersonally. All individuals in the leveled down society have the same interpersonal luck, and hence no one has bad luck in that sense. However, relative to the life of control, they all have bad luck, in that they have less access to advantage than they might have had, albeit to the same extent. It is this, counterfactually specified, luck that luck-neutralizers wish to neutralize by ensuring that individuals live a life of control.

Up to this point, nothing egalitarian has been said. It has merely been argued that a life of control, in which luck plays no part, is a life in which one has access to every level of advantage in society. However, a substantial egalitarian component does arise if we expand luck-neutralization to all members of society. This is necessary to have a distribution in which no individual's level of advantage is determined by luck, as is stipulated by the ideal of luck-neutralization. For luck to be neutralized in a particular society, luck must be neutralized for all members of that society, by giving everyone a life of control. This means ensuring that everyone in society has access to every level of advantage. In such a society, the distribution of benefits does not depend on luck for anyone. How well off individuals are is entirely within their control. However, such a distribution would be relevantly egalitarian in its pattern of distribution. From the general requirement that all individuals must have access to every level of advantage we may conclude that such a society would grant all its members equal access to advantage, where access to advantage takes into account how difficult it is to achieve advantage. This is simply a logical consequence of universalizing the life of control. If we give everyone every opportunity, we give everybody the same opportunities. In this way, a society that neutralizes luck is characterized by universal access to every available advantage. A society that offers some people more access to advantage than others is inherently sub-optimal from the perspective of luck-neutralization. This is the case, not because of the inequality as such, but because such a society does not offer all its members access to every available level of advantage. If some people have access to more advantages than others, the people who are disadvantaged may say that there are some levels of advantage they do not have access to, as evidenced by the people with more advantages. This should be remedied according to the ideal of 
luck-neutralization, thereby justifying an egalitarian pattern without relying on any values foreign to luck-neutralization.

For example, we might imagine a society composed of two individuals, Jack and John, who both have access to two levels of advantage. It may be assumed that the levels of advantage are associated with jobs they can get. Jack can become a baker or a butcher, which would yield him thirty or fifty units of advantage respectively. John, who happens to have been born with more talents than Jack, can become a banker or a management consultant, which would yield him eighty or one hundred units of advantage respectively. In sum, luck has arranged things in such a way that John has better access to advantage than Jack. This example is paradigmatic of the inequalities of access to advantage that permeate our society. We may ask what sort of action would be required to neutralize luck in this example.

According to luck-egalitarianism, as it is traditionally understood, we must object to the inequality of access to advantage and equalize it through redistribution. Society should institute a taxation-scheme that seeks to make Jack's options less attractive and John's options more attractive. In this way, equality of advantage could be achieved, given the limited resources society has available. By redistributing the payoffs associated with the various options available to individuals, equality of access could be attained. Both Jack and John would then have choices that lead them to, say, fifty-five and seventy-five units of advantage. The idea is that by equalizing access to advantage, which embodies the influence of luck, luck is neutralized. To this proposal Hurley rightly objects. This argument for equality of access to advantage does not rely exclusively on luck-neutralization, but relies on the idea that equality in distribution would somehow undo the influence of luck. This argument makes equality the default position, thereby including it in the premises.

But the present understanding of luck-neutralization escapes this problem. Confronted with the access to advantage Jack and John have, a devotee of universal access to every available advantage objects not to the inequality as such, but to the fact that they do not have access to every level of advantage in society. Given the fact that John has access to one hundred units of advantage, that level of advantage is apparently available in society. Jack may protest that he does not have access to that level, and that this shows that he does not have access to every level of advantage in society. In this way, where he ends up is not entirely within his control; he could not end up with one hundred or eighty units of advantage, despite the fact that this level is apparently available in society. In this way, he does not object to the inequality for the sake of equality, but because of the fact that it shows that he does not have access to every level of advantage. Something similar goes for John, who lacks access to the lower levels of advantage. If we wish to give Jack and John access to every available level of advantage, we must alter their choice-sets. The question is, in what way should we do that and at whose expense.

In terms of the ideal of luck-neutralization, society must expand access to advantage to conform to the social menu. To achieve this, we might start by ensuring that Jack would also have options that would yield him eighty and one hundred units of advantage, and that John also has access to thirty and fifty units of advantage. In this way, both Jack and John would have access to every level of advantage evidently available in society. As a consequence, they have access to the 
same levels of advantage, producing an egalitarian pattern of distribution, making the proposal egalitarian. It might be the case that society can also offer them other levels of advantage, including some levels that are more advantageous than the levels initially observed. Luck-neutralizers require that they both be given access to the levels. However, it is also possible that there are too few resources to give both Jack and John access to certain levels of high advantage, because if they were to both exercise their access there would not be enough advantage to go around. Given limited resources, it might be possible to offer levels of advantage to some individuals but not to others. If this is the case, satisfying luck-neutralization requires that the levels of advantage not be made available at all. In this way, access to advantage is to be redistributed in such a fashion that all members of society have access to every level of advantage that can be made generally available, given the resources of society. It might well be the case that this results in a distribution of access to advantage that is identical to the one that Cohen's notion of equality of access to advantage would require. However, this does not come about as a consequence of an external commitment to equality. It is not assumed that distributing access equally neutralizes luck; the result is based on the idea that for luck to be neutralized someone must have access to every available level of advantage.

Universal access to every available advantage satisfies the egalitarian constraint. Satisfying it requires that access to advantage be distributed in an egalitarian fashion. If a pattern of distribution is characterized by inequality of advantage, luckneutralizers will require that access to advantage be redistributed to an egalitarian pattern. Indeed, universal access to every available advantage is almost identical to Cohen's version of luck-egalitarianism in consequence. There is only one area of concrete difference between the two theories, and it is technical. Cohen's theory would be satisfied if all individuals have equal access to advantage, even if it were possible to universally increase access to advantage. Satisfying the theory of justice under consideration would require that this increase be implemented. But this might be offered as a friendly amendment to Cohen's theory, as it seems unlikely that he would be opposed to expanding access to advantage for everyone, at no cost to equality.

It is important to note that the equality that would characterize a society in which luck plays no role is not generated by any substantial commitment to equality that is external to luck-neutralization. It is derived from universalizing the notion of a life of control, as is required by the ideal of luck-neutralization. In a sense, it is a logical by-product, although an important one. Hence, the equality is not assumed in the premises, ensuring that the argument does not beg the question. "Luck" or "control" have not been defined relative to any type of equality, nor is there anything inherently egalitarian in a life of control as "a life of control" was not defined in comparative terms. However, the conclusion is egalitarian, in that it would have us stipulate an egalitarian distribution of access to advantage.

Someone might object that in the inference from an individual life of control to a luck-neutralized society some fallacy is committed, in that in such a society everyone lives a life of control to the same extent. In this way, the argument relies 
on an egalitarian conception of fairness, such as the one defined by John Broome. ${ }^{22}$ Satisfying this conception of fairness requires that individuals have their claims, in this case their claim to a life of control, satisfied to an equal extent. A life of control is said to be a life of having access to advantage, and everybody should have a life of control to the same extent, which leads to the conclusion that all individuals should have equal access to advantage, but only by virtue of the equality assumed in the second premise through fairness. This argument would be question-begging in the relevant sense. However, this is not the argument under consideration. It has not been argued that luck-neutralizers hold that all individuals should have the same options as such, but that all individuals should have every option in order to live a life of control. This happens to imply that all individuals should have the same options, but this is not assumed in the premises through a commitment to fairness. To see this, let us consider that fairness, as Broome conceives of it, is fundamentally a second-best concept. Ideally, all claims should be satisfied. It is only when all claims cannot be satisfied that fairness comes in, requiring that all claims at least be satisfied equally. But as luck-neutralization is currently under discussion in an ideal sense, fairness does not play any role.

\section{Breaking the Luck-Neutralizer's Dilemma}

Hurley introduces her arguments by reflecting on what she calls the egalitarian fallacy. People who commit this fallacy infer from "It is a matter of luck that two individuals are unequal" that "it would not be a matter of luck if these individuals were equal." ${ }^{23}$ This inference is plainly fallacious, as it is not the case that an equal distribution would somehow not be a matter of luck. As Hurley notes, this is not the case, as it is possible that two individuals are equal in some currency through the operation of luck. However, this fallacy does not pose a threat to the present understanding of luck-neutralization. It has already been established that the currency under consideration is access to advantage. By definition, someone is not responsible for the access to advantage he or she enjoys. This is always a matter of luck, regardless of how it is distributed. Satisfying the ideal of luck-neutralization does not require that this be altered. What is required is that the levels of advantage that individuals come to enjoy depend only on their choices. The question is how access to advantage should be distributed in order to achieve this aim. When access to advantage is distributed in such a way that someone has access to every available level of advantage, the levels individuals come to enjoy depends only on factors over which they have control. Establishing such a pattern does not change the fact that the access to advantage someone enjoys is a matter of luck. Nothing could change that, just as nothing could change the fact that whether someone exists is a matter of luck. But it does ensure that luck plays no part in the distribution of levels of advantage, and this is what satisfying the ideal of luck-neutralization requires in the context. In this way, the egalitarian fallacy is not a challenge to that ambition.

\footnotetext{
${ }^{22}$ See John Broome, "Fairness," Proceedings of the Aristotelian Society, vol. 91 (1991).

${ }^{23}$ Hurley, op. cit., p. 152.
} 
With this understanding of luck-neutralization in hand, it becomes possible to see how universal access to every available advantage is resistant to the luckneutralizer's dilemma. It becomes clear that all luck is bad, since for luckneutralizers any influence of luck detracts from the life of control that they deem desirable. Luck manifests itself as not having access to every level of advantage. If we have very much access to advantage, then we are luckier than if we have less access to advantage. Our access to advantage can be compared to the social menu, thereby establishing a non-interpersonal standard for bad luck, as having a more limited decision tree than the social menu. This is always undesirable from the perspective of luck-neutralization. It is possible that someone has access to every available level of advantage through the operation of luck. While this distribution would be a matter of luck, it ensures that the level of advantage someone comes to occupy is determined solely by his or her choices and neutralizes luck in the relevant sense. As it is impossible to have access to more than every available level of advantage, there is no such thing as good luck. There is good luck in a familiar sense, where someone happens to have more access to advantage than others. But from the perspective of luck-neutralization, this is merely a case of someone being closer to enjoying a life in which luck does not affect how well off he or she is than others.

Luck in this sense is counterfactual, as in the second horn of the luckneutralizer's dilemma. But it is a different type of counterfactual luck, one that Hurley neglects. When Hurley considers the counterfactual specification of luck, she compares an individual's actual luck to the best possible position the individual might have been in, and she is correct in noting that there is no reason to think that putting all individuals in that situation would result in an egalitarian pattern of distribution. But the particular counterfactual relative to which luck is defined is access to every available level of advantage, as specified in the social menu. This standard is justified by the fact that in order for luck not to have any influence over how well off we are, this must only be a function of our choices. When luck is defined in this fashion, the second horn of the dilemma loses its sharpness. If we neutralizes luck in this sense, the result is a society in which all members have access to every level of advantage. Such a distribution would indeed be egalitarian. Luck is neutralized when all individuals are in the best world possible with regard to luck-neutralization, and such a world would be characterized by an egalitarian pattern of distribution. While Hurley does not consider this understanding of counterfactual luck, even when she considers what it would mean to put everyone in the best world possible for them, this is the proper understanding of luck from the perspective of luck-neutralization. Neutralizing luck, when defined in this fashion, does lead to an egalitarian pattern of distribution of access to advantage.

Hurley makes ingenious arguments against the idea that luck-neutralization can justify an egalitarian theory of justice. Her arguments certainly show that luckegalitarianism as it has been elaborated in the past cannot be based on luckneutralization. In this way, she challenges luck-egalitarians to rethink the foundations of their theory of justice. Universal access to every available advantage, designed to meet the challenge of justifying an egalitarian theory of justice based on the ideal of luck-neutralization, was born of that challenge. In this way we may 
credit Hurley with forcing luck-egalitarians to re-examine the fundamentals of their theory. However, as we have seen, the inspiring and morally important ideal of luck-neutralization can be used to justify something relevantly similar to luckegalitarianism. Instead of having to rely on controversial ideals, such as equality or desert, the mere desire to eradicate the influence of luck on distribution is a reason to institute an egalitarian pattern of distribution. ${ }^{24}$

Open Access This article is distributed under the terms of the Creative Commons Attribution Noncommercial License which permits any noncommercial use, distribution, and reproduction in any medium, provided the original author(s) and source are credited.

\footnotetext{
${ }^{24}$ This article was written while in residence as a Research Affiliate at the Department of Political Science, Yale University. I would like to thank the University and the Department for their warm and generous hospitality. In particular, I am indebted to John E. Roemer for inviting me. I am also grateful to G.A. Cohen for his support and constructive remarks in writing the article. Lastly, I would like to record my gratitude to three anonymous referees and Thomas Magnell, the Editor-in-Chief of the Journal of Value Inquiry, for their extraordinarily generous comments and help.
} 